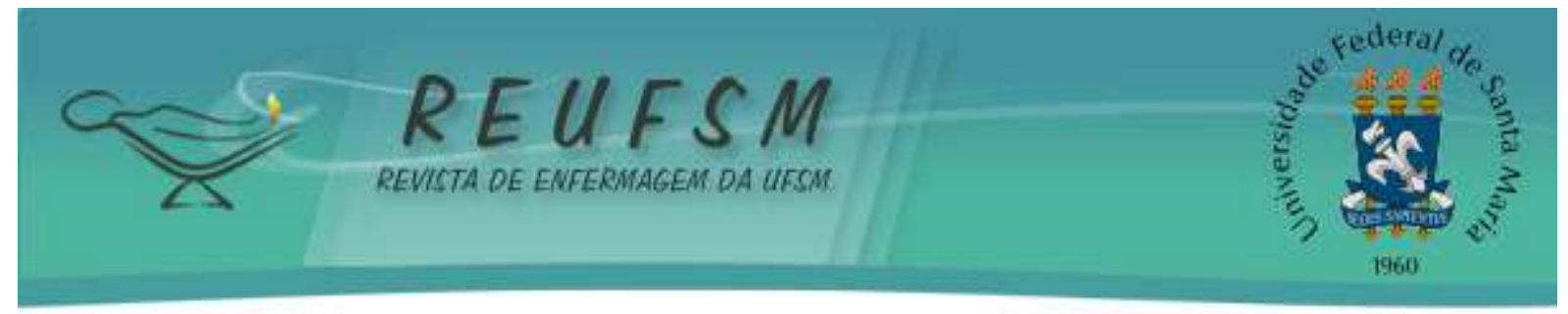

ARTIGO ORIGINAL

\title{
REDES DE ATENÇÃO À SAÚDE NO VER-SUS OESTE CATARINENSE: CONTRIBUIÇÕES PARA O ENSINO EM ENFERMAGEM
}

\section{HEALTH CARE NETWORKS IN WESTERN SANTA CATARINA'S VER-SUS: CONTRIBUTIONS TO NURSING TEACHING \\ REDES DE ATENCIÓN DE LA SALUD EN EL VER-SUS OESTE CATARINENSE: CONTRIBUICIONES PARA LA ENSEÑ̃̃NZA EN ENFERMERÍA}

\author{
André Lucas Maffissoni ${ }^{1}$ \\ Carine Vendruscolo ${ }^{2}$ \\ Letícia de Lima Trindade ${ }^{3}$
}

Doi: $10.5902 / 2179769225853$

RESUMO: Objetivo: discutir as contribuições do Programa Vivências e Estágios na realidade do Sistema Único de Saúde para o estudo das Redes de Atenção à Saúde e sua operacionalização no âmbito do Sistema Único de Saúde, na perspectiva de estudantes de Enfermagem. Método: pesquisa qualitativa, desenvolvida a partir de entrevistas com estudantes participantes do Programa entre 2014 e 2016, em Santa Catarina, cujos dados foram tratados mediante análise temática. Resultados: o estudou revelou o Programa como estratégia que contribui significativamente para a aprendizagem dos estudantes sobre Redes, ao promover a inserção dos mesmos no contexto do serviço, incentivando a práxis e contribuindo, inclusive, para a educação permanente dos profissionais desta rede. Conclusão: salienta-se a importância de proporcionar e ampliar o acesso dos estudantes em programas/vivências dessa natureza, no âmbito da formação em Saúde e Enfermagem, o que poderá colaborar para o fortalecimento do sistema de saúde.

Descritores: Serviços de saúde; Sistema único de saúde; Educação em saúde; Enfermagem; Ensino.

ABSTRACT: Aim: to discuss the contributions of the Program of Experiences and Training in the Reality of the Unified Health System for the study of Health Care Networks and its operationalization in the Unified Health System on the basis of Nursing students' perspectives. Method: qualitative and descriptive research developed from interviews carried out with the students who participated in the Program between 2014 and 2016, in Santa Catarina. The data were analyzed through thematic analysis. Results: the study revealed the Program as a strategy that contributes significantly to students' learning about Networks, promoting their inclusion in the context of the service, encouraging the práxis and also contributing to the professional's permanent education of the network. Conclusion: the importance of providing and enlarging the access of the students at programs/experiences of

\footnotetext{
${ }^{1}$ Estudante de graduação em Enfermagem da Universidade do Estado de Santa Catarina, Chapecó, SC, Brasil. Email: andremaffissoni@hotmail.com

${ }^{2}$ Doutora em Enfermagem. Professora adjunta do Departamento de Enfermagem e Mestrado Profissional em Enfermagem na Atenção Primária à Saúde da Universidade do Estado de Santa Catarina. Email: carine.vendruscolo@udesc.br

${ }^{3}$ Doutora em Enfermagem. Professora adjunta do Departamento de Enfermagem e Mestrado Profissional em Enfermagem na Atenção Primária à Saúde da Universidade do Estado de Santa Catarina e do Programa de PósGraduação em Ciências da Saúde da Unochapecó. Email: letrindade@ @otmail.com
} 


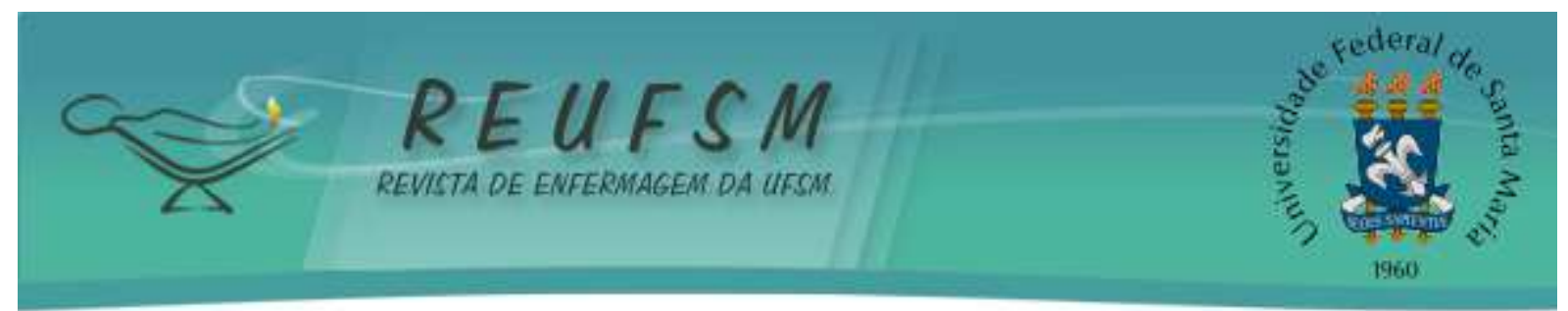

this nature, in the scope of Health and Nursing training, is emphasized, once it can collaborate to the strengthening of the health system.

Descriptors: Health services; Unified health system; Health education; Nursing; Teaching.

RESUMEN: Objetivo: discutir las contribuciones del Programa de Experiencias y Pasantías en la Realidad del Sistema Único de Salud para el estudio de las Redes de Atención a la Salud y su operacionalización en el ámbito del Sistema Único de Salud, a partir de la perspectiva de estudiantes de Enfermería. Método: investigación cualitativa desarrollada por medio de entrevistas con estudiantes participantes del Programa entre 2014 y 2016, en Santa Catarina, cuyos datos fueron analizados con base en análisis temático. Resultados: El estudio reveló el Programa como una estrategia que contribuye significativamente para el aprendizaje de los estudiantes sobre las Redes, porque promueve la inserción en el contexto del servicio, incentivando la praxis y contribuye, incluso, con la formación continuada de los profesionales de esta rede. Conclusión: se destaca la importancia de proporcionar y ampliar el acceso de los estudiantes a programas/vivencias de esta naturaleza, en el ámbito de la formación en Salud y Enfermería, lo que puede colaborar para el fortalecimiento del sistema de salud.

Descriptores: Servicios de salud; Sistema único de salud; Educación en salud; Enfermería; Enseñanza.

\section{INTRODUÇÃO}

As Redes de Atenção à Saúde (RAS) são definidas como um conjunto de ações e serviços em saúde articulados por meio de níveis de complexidade e capazes de garantir a integralidade da assistência em saúde. ${ }^{1}$ A organização em RAS promove relações horizontais entre os pontos de atenção, assim como entre os profissionais; centraliza a assistência nas necessidades individuais; promove o compartilhamento de informações para a condução dos itinerários terapêuticos; e conta com a Atenção Primária à Saúde como centro de comunicação. ${ }^{2}$ Além disso, o modelo em RAS tem sido evidenciado como um meio para racionalizar e melhor aproveitar os recursos em saúde, ofertando atendimento na hora certa, do modo certo e com as tecnologias em saúde necessárias. ${ }^{3-4}$

A dinâmica dos serviços que compõe uma Rede no âmbito do Sistema Único de Saúde (SUS) é essencial para uma atenção efetiva e qualificada. Logo, ressalta-se a magnitude da temática para a formação em saúde, sobretudo em Enfermagem, devido às diversas funções assistenciais e gerenciais desenvolvidas por estes profissionais no mercado de trabalho.

O ensino em Enfermagem é fortemente influenciado por práticas pedagógicas tradicionais, nas quais o papel do professor é central e o estudante não participa ativamente do processo. Essa característica formal de educação emergiu no Ocidente com a ascensão do capitalismo e da industrialização, que buscaram materializar e institucionalizar os processos educativos, ${ }^{5}$ e está enraizada em diversos campos dos saberes. Em decorrência disso, se estabeleceu uma metodologia 


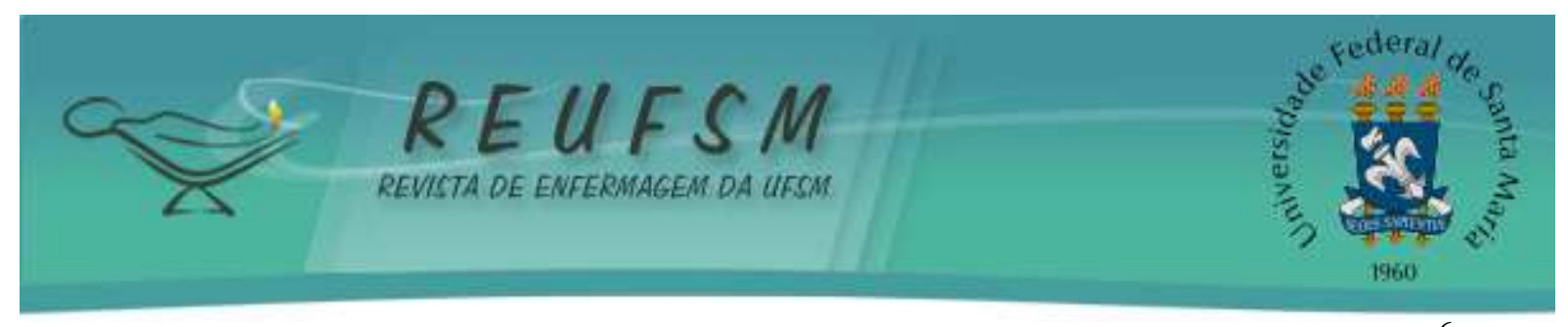

de aprendizagem fragmentada, reducionista e orientada pelo método bancário de ensino, ${ }^{6}$ o que reflete negativamente na qualidade da formação dos profissionais.

A superação desse modelo de educação é estimulada há anos por diversas personalidades e instituições, ${ }^{7}$ no entanto, persistem os obstáculos para formar profissionais humanistas, críticos e reflexivos, como preconizam as Diretrizes Curriculares Nacionais (DCN) do Curso de Graduação em Enfermagem. ${ }^{8-9}$

Nesse sentido, na tentativa de minimizar as lacunas da formação tradicional e qualificar os processos formativos, emergem dispositivos de ensino que incorporam a prática à teoria, por meio da integração ensino-serviço, como é o caso do Programa Vivências e Estágios na realidade do Sistema Único de Saúde (VER-SUS). O VER-SUS é uma proposta que busca qualificar a formação em Saúde e direcionar as graduações nesta área ao estudo das características do SUS. ${ }^{10}$

Assim, durante as atividades do Programa, são realizadas inúmeras ações reflexivas que buscam instigar o pensamento crítico e a corresponsabilização dos estudantes em relação aos aspectos que envolvem o SUS e a educação/formação em saúde.

O VER-SUS é desenvolvido em diferentes regiões e municípios do Brasil, e conta com diversas instituições públicas de Saúde e Instituições de Ensino Superior (IES) como apoiadoras e colaboradoras. O programa culminou da criação da Assessoria de Relações com o Movimento Estudantil e Associações Científico-Profissionais de Saúde que, inicialmente, procurou estreitar as relações de estudantes com o Ministério da Saúde para colaborar na formulação de políticas de educação para futuros profissionais. ${ }^{10}$

Em Santa Catarina, o VER-SUS já foi realizado nos municípios de Florianópolis (VERSUS Florianópolis), Vale do Itajaí (VER-SUS Foz do Rio Itajaí) e Chapecó (VER-SUS Oeste Catarinense). O VER-SUS Oeste Catarinense teve, em algumas edições, as RAS como tema principal. Esta temática foi escolhida pela comissão organizadora local em razão de ser um conteúdo relevante para todos os profissionais da saúde e por suas potencialidades enquanto modelo de atenção, além de que sua efetivação no SUS tem sido estimulada pelo Ministério da Saúde. ${ }^{1-3}$ Salienta-se que o tema norteador do programa em outras regiões pode ser outro, a critério das características locorregionais e da trajetória acadêmica e profissional dos organizadores.

Nessa região, o programa atua de modo a estimular o senso crítico dos estudantes, permitindo que visualizem os obstáculos existentes no contexto da saúde e fomentando a reflexão de como podem ser superados. ${ }^{11}$ Estudantes $^{12}$ descrevem que o VER-SUS teve 


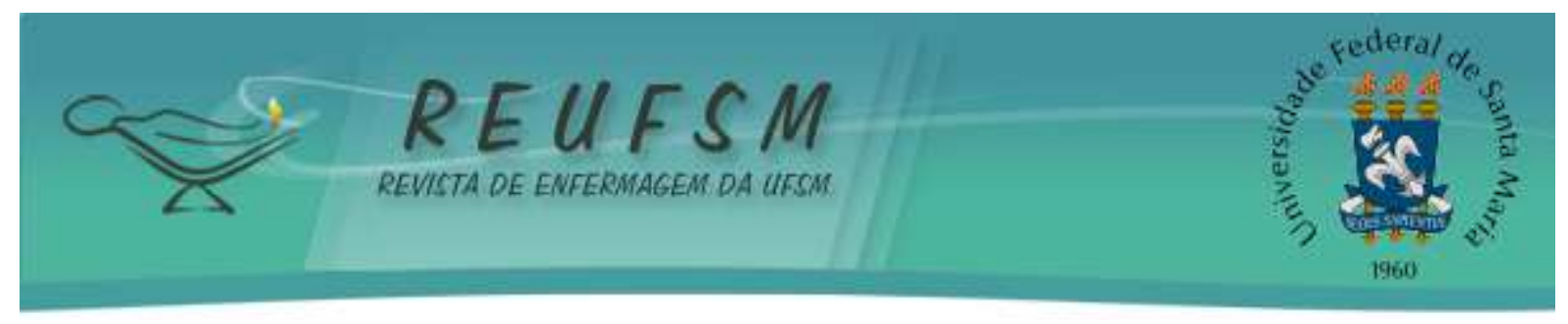

importante papel para compreender a gestão e o gerenciamento de ações no SUS, dentre as quais, pode-se destacar a dinâmica de trabalho em redes de atenção.

Assim, pesquisar características sobre o Programa é importante para auxiliar nas reflexões que envolvem a formação em saúde voltada ao contexto da efetivação das RAS como elemento organizativo do SUS. Estudos com esse escopo são prioridades em pesquisa na área de Enfermagem na América Latina, segundo estudo recente. ${ }^{13}$

Diante disso, a presente pesquisa partiu da pergunta: quais as contribuições do Programa VER-SUS na formação, para o (re)conhecimento das RAS e sua operacionalização no SUS? Elaborou-se, assim, o seguinte objetivo para respondê-la: discutir as contribuições do Programa Vivências e Estágios na realidade do Sistema Único de Saúde para o estudo das Redes de Atenção à Saúde e sua operacionalização no âmbito do Sistema Único de Saúde, na perspectiva de estudantes de Enfermagem.

\section{MÉTODO}

Trata-se de uma pesquisa qualitativa, descritiva, desenvolvida em duas IES públicas do Oeste de Santa Catarina.

Como critérios de inclusão, os participantes deveriam: ter idade igual ou maior que 18 anos; estar matriculados no último ano da graduação de acordo com o Projeto Pedagógico dos Cursos ( $9^{\circ}$ ou $10^{\circ}$ semestre); ter participado em, pelo menos, uma edição do VERSUS; e ter cursado, no mínimo, $50 \%$ do total de horas do curso nas IES pesquisadas.

Mediante convite prévio, encaminhado via e-mail, responderam positivamente para participar da pesquisa 15 estudantes, dos quais sete já participaram do VER-SUS em edições anteriores.

Os dados foram obtidos a partir de entrevistas semiestruturadas, realizadas nos meses de junho e julho de 2016. As questões versaram sobre a importância das atividades desenvolvidas no VER-SUS para fomento das RAS e sobre as influências do Programa no itinerário formativo de acadêmicos de Enfermagem em relação à construção do seu ideário a respeito da temática das Redes.

As informações foram tratadas utilizando a proposta da análise temática de Bardin, ${ }^{14}$ na qual as informações são extraídas das falas por meio da contagem de temas ou itens de significação e agrupadas mediante codificação previamente determinada, a fim de compreender as explicações particulares dos participantes acerca do tema. Assim, posteriormente à transcrição das entrevistas, foi 


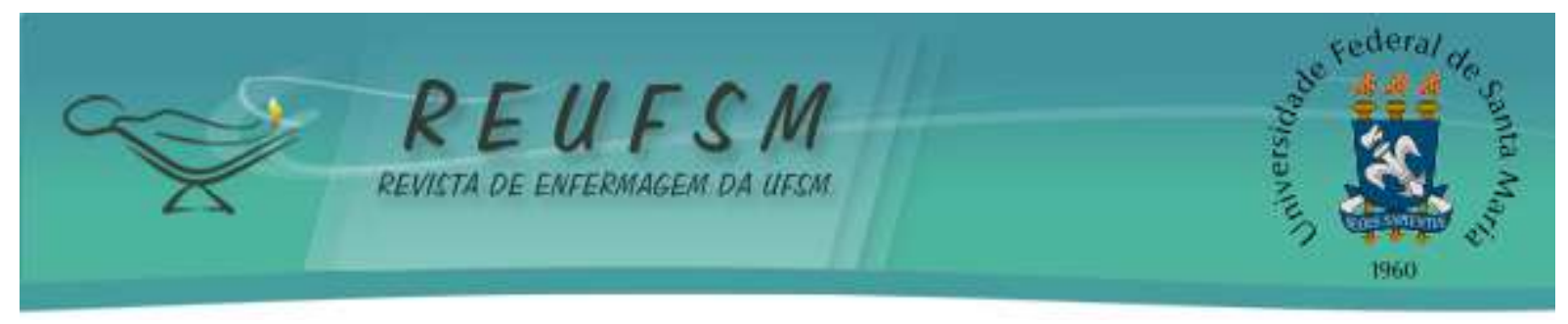

realizada leitura exaustiva do material, extraídas as unidades de registro e agrupadas as frases com significado temático semelhante, em relação ao objeto pesquisado. Esse processo deu origem às duas categorias temáticas: "VER-SUS: oportunidade para conhecer a Rede" e "Compreendendo a operacionalização das Redes por meio da integração entre o ensino e o serviço".

A presente pesquisa foi realizada após aprovação do Comitê de Ética em Pesquisa da Universidade do Estado de Santa Catarina (UDESC) em 17 de maio de 2016, sob Certificado de Apresentação para Apreciação Ética (CAAE) 54362016.5.0000.0118. Com o intuito de preservar a identidade dos participantes e também das IES, ao revelar as falas, seus nomes foram substituídos pela letra $\mathrm{E}$ de Estudante, seguida por número correspondente à ordem da entrevista.

\section{RESULTADOS E DISCUSSÃO}

Na Região Oeste de Santa Catarina o Programa VER-SUS é realizado desde o ano de 2014. O período de atividade é composto por, em média, sete dias e ocorre com frequência semestral. Os participantes são imersos de forma integral na realidade do SUS, a partir de visitas às instituições de saúde e de discussões sobre diversos temas que permeiam o processo de produção de saúde e de conhecimento nessa área.

Dentre os locais visitados pelos estudantes, pode-se citar: Unidades Básicas de Saúde (UBS), Centros de Atenção Psicossocial (CAPS), Hospitais (regionais e municipais), Centros de Atendimento Odontológico, Rede Feminina de Combate ao Câncer, Vigilância Epidemiológica, Centros de Referência em Direitos Humanos, Aldeias Indígenas e Centros de Referência em Saúde do Trabalhador. Além disso, foi possível que os viventes (estudantes participantes pela primeira vez no programa) participassem de reuniões com a população local, por meio dos conselhos locais e municipais de saúde, assim como de uma conferência municipal de saúde, nos quais tiveram contato com representantes de movimentos sociais, usuários do SUS e outros segmentos sociais.

Até o primeiro semestre de 2016 foram realizadas quatro edições do VER-SUS, abrangendo um total de 224 estudantes e 22 áreas do conhecimento, não exclusivamente da saúde. ${ }^{12}$

Em relação aos participantes desta pesquisa, uma estudante participou em quatro edições do VER-SUS; duas participaram em três edições; três estudantes participaram em duas edições; e uma estudante participou em uma edição do Programa. As funções desempenhadas por elas foram: viventes (estudantes participantes pela primeira vez no Programa); facilitadores (estudantes que já 


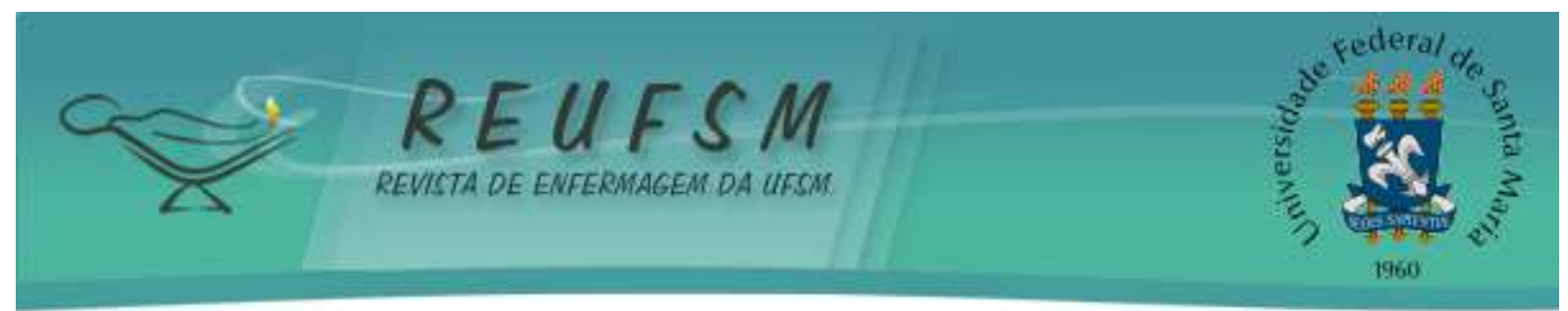

participaram do VER-SUS e que possuem a função de auxiliar os viventes nas visitas e discussões) e como membro da comissão organizadora.

É importante ressaltar também que todas as estudantes pesquisadas são do gênero feminino e que a idade variou entre 21 e 39 anos. Seus relatos frente aos questionamentos deram origem às categorias temáticas, que são apresentadas e discutidas a seguir.

\section{VER-SUS: oportunidade para conhecer a Rede}

Os dados revelaram que, para os estudantes de Enfermagem, a participação no projeto VERSUS foi um dos únicos momentos na graduação em que tiveram maior contato com as RAS:

Eu tive mais contato ali no VER-SU. Na graduação em si eu não tive muito contato, e não lembro de terem falado especificamente sobre RAS. (E1)

[...] Tive [contato com as RAS] também no VER-SUS, que eu participei da Rede de Atenção Psicossocial (RAPS), que eu tive um conhecimento maior de como funciona essa Rede específica. (E2)

Eu tive contato com o assunto Redes mesmo, no projeto VER-SUS, que eu fui parte da comissão [organizadora]. Mas é isso, só tive esse contato no VER-SUS. (E3)

Eu vi mais [sobre as RAS] no ano passado, começo desse ano, quando eu participei do VER-SUS, que o tema era Redes. (E4)

[...] tive um pouco de contanto no VER-SUS, que eu tive um pouco de contato com as RAS na segunda edição, e foi por isso que eu me interessei por esse tema para o TCC [Trabalho de Conclusão de Curso]. (E5)

Os dados demonstram que o ensino da graduação não tem problematizado, suficientemente, o modelo de atendimento em forma de RAS.

Essa lacuna em relação à abordagem das RAS pode estar atrelada às diversas fragilidades que permeiam a formação em saúde e que limitam um processo formativo voltado às características e demandas dos SUS: os currículos rígidos, geralmente direcionados à prática hospitalar; o modelo de saúde que permanece desenvolvendo ações com foco na cura de doenças agudas; a falta de compromisso dos sujeitos que estão envolvidos no processo; $;{ }^{15}$ a ausência de estratégias capazes de estimular o futuro profissional ao enfrentamento de conflitos e dilemas do mundo do trabalho; ${ }^{16} \mathrm{e}$ as dificuldades em trabalhar questões gerenciais. ${ }^{17}$

Apesar dessas dificuldades, há que se compreender que a abordagem das particularidades do SUS na formação é fundamental para que existam mudanças positivas na atenção à 


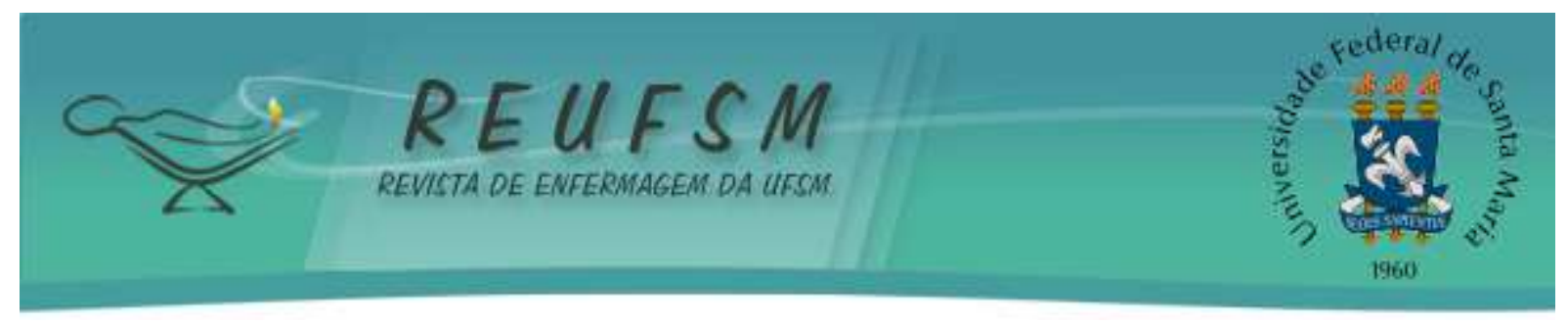

saúde no contexto do Sistema. Essa necessidade é evidenciada, pelo menos, desde 2001, quando o Ministério da Educação aprovou as DCN para os cursos da área da saúde e também para a Enfermagem. As Diretrizes enfatizam a adequação da formação profissional às necessidades do SUS, bem como, reforçam o papel protagonista dos sujeitos envolvidos, ressaltando que estes devem comprometer-se com a educação permanente e continuada das futuras gerações de profissionais, especialmente potencializadas e dependentes da integração ensino-serviço. ${ }^{8-9}$

Tendo em foco a realidade atual do Sistema e as deliberações que orientam a formação na área da saúde, considera-se a necessidade de incorporar o tema RAS nas vivências teóricas e práticas dos estudantes da área, sobretudo da Enfermagem, já que esses futuros profissionais deverão assumir funções no âmbito do cuidado, da educação e da gestão em saúde.

A relação entre o ensino e o mundo do trabalho é inegável, pois no momento em que o ensino se qualifica, a qualidade dos serviços também aumenta. É fato que a mudança que se deseja no modelo de atenção que orienta o SUS só será possível a partir de transformações nos processos formativos. Desta forma, é importante conhecer o serviço durante a formação; colocar-se a disposição de aprender com e no mundo do trabalho, produzindo experiências e preparando-se para fazer parte dele. ${ }^{18}$

Para compreender o impacto que os movimentos do ensino nas discussões em torno das RAS geram no trabalho em saúde, faz-se necessário ampliar as percepções de como a saúde é acessível e de como a atenção pode qualificar-se quando se trabalha na dinâmica das Redes. Além disso, é preciso esclarecer as relações entre a formação e o trabalho em saúde; são dois setores interligados por diversos segmentos, sendo intrínseca a repercussão das ações de uma esfera sobre a outra. ${ }^{18}$

O VER-SUS exerce importante papel no sentido de fazer o estudante encontrar-se com o tema das RAS, o que pode ser percebido na leitura dos dados. Os estudantes de Enfermagem demonstraram que, a partir do VER-SUS, tiveram a chance de discutir e compreender de forma mais clara as Redes no cotidiano do SUS. 


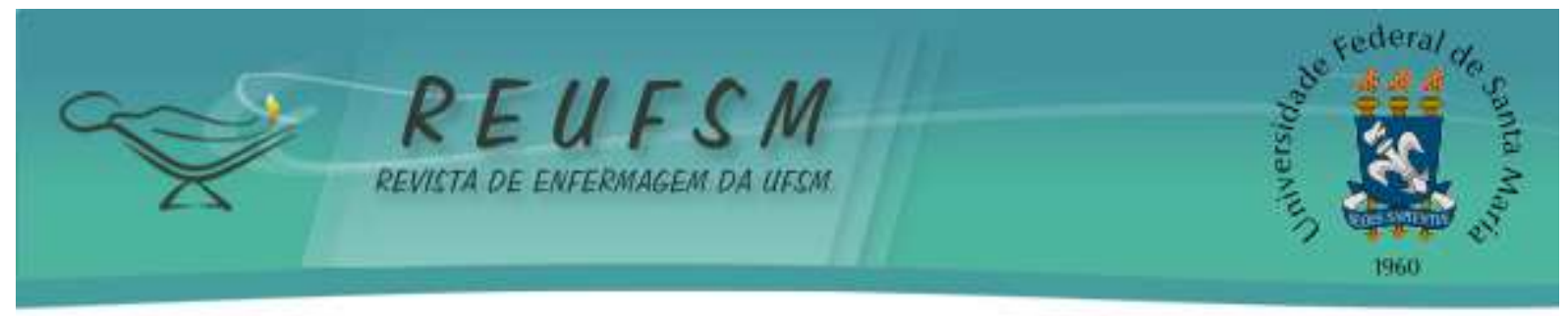

Compreendendo a operacionalização das Redes por meio da integração entre o ensino e o serviço

A participação no Programa VER-SUS também contribui para aprendizagem sobre as RAS, a partir da troca de saberes com os profissionais no cotidiano do trabalho, o que caracteriza movimentos de integração entre o ensino e o serviço.

No VER-SUS você vê na prática isso [as RAS], você consegue vivenciar o caminho que o paciente vai fazer e também você consegue questionar os funcionários de cada instituição de como o paciente chega até ali, o que se faz se ali não está sendo atendido e como vai fazer para passar para frente dali [...] Se ele tem que voltar para a Unidade [Unidade Básica de Saúde] ou se ele vai continuar o tratamento dali [...] É ali que se percebe que a Rede está realmente funcionando. (E6)

Acho que na minha formação faltou vivenciar o que são as Redes na prática. Eu vivenciei de outra forma, através de projetos tipo o VER-SUS. [...] porque uma coisa é a gente ver no papel, nos cadernos, outra coisa completamente diferente é a gente conhecer essa realidade e entender como é que os profissionais se guiam ou eles não se guiam, se é mais fácil ou é mais complicado, então é diferente a prática do que se espera, e eu consegui ver isso. (E7)

A parte que o VER-SUS me trouxe, que me colocou lá na prática, me colocou em cada local, cada ponto dessa rede, todos os locais que ele [o VER-SUS] me levou, todos os locais que o paciente teria que passar. A partir do momento que eu vivi a rede, vi todo o percurso que o paciente tem que passar, eu me sinto mais preparada em relação às $R A S$. (E2)

Os dados demonstram que a integração entre educação e trabalho permeou as vivências realizadas. "Viver a Rede", para os estudantes, contribuiu para a produção e compartilhamento de conhecimentos sobre a temática.

Acredita-se que, para a qualificação da atenção no SUS, é necessário que ocorram diversas modificações nos processos formativos, dentre as quais destacam-se a necessidade de contato dos estudantes com os profissionais, com a gestão setorial e com o controle social em saúde. Assim, é importante ressaltar que, dentre os princípios que "regem" a organização das edições do VER-SUS no Oeste Catarinense, está o comprometimento com a exposição dos estudantes a estratégias de aprendizagem que incorporem a participação efetiva do Quadrilátero da Formação para a Área da Saúde ${ }^{19}$ (gestão, atenção, ensino e controle social).

Esse ideário adotado pelo VER-SUS, visa à construção e à gestão da educação na saúde no âmbito do SUS, a partir da ilustração de uma figura na qual cada face representada no 


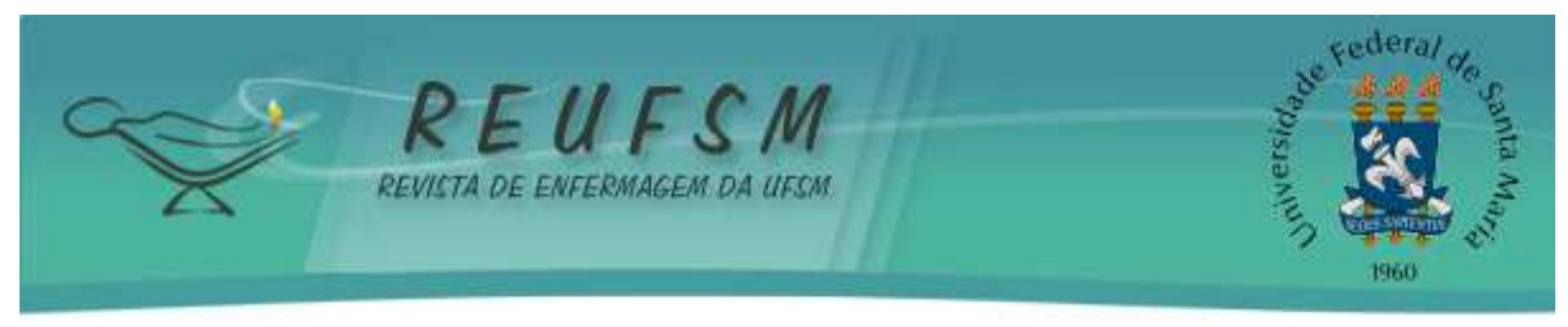

quadrilátero estabelece fluxos e interlocutores específicos, em espaços-tempos e com motivações diferentes, numa trama de conexões. ${ }^{19}$ Acredita-se que a interação efetiva entre os segmentos que fazem parte do quadrilátero produz maior comprometimento dos sujeitos, por meio de relações de vínculo e responsabilização entre estudantes, usuários, professores, profissionais, gestores e outros parceiros na produção dos processos de educação e de cuidado em saúde. ${ }^{20}$

A troca mútua de informações que ocorre durante o contato dos estudantes com o serviço e a comunidade tangencia e, com o passar do tempo, influencia o cotidiano do trabalho e da educação em saúde. Ao possibilitar que o acadêmico experimente esse vínculo mediante as oportunidades no VER-SUS, permite-se também que a produção do conhecimento ocorra na prática do dia-a-dia, quando os estudantes podem conhecer e reconhecer a micropolítica do trabalho vivo em ato, ${ }^{21}$ ou seja, a micropolítica dos elos existentes entre usuários e profissionais. Assim, são aproximados das reais necessidades da população e dos aspectos que necessitam ser aperfeiçoadas nas instituições de saúde.

As prerrogativas resultantes dos processos de integração ensino-serviço legitimam a relevância da estratégia para qualificar a formação em saúde. ${ }^{6}$ No caso das RAS, utilizar deste meio para expor aos estudantes o trabalho compartilhado de produção de itinerários terapêuticos no âmbito da Rede é muito válido, devido à complexidade de visualizar a dinâmica de fluxos dentro das RAS somente em teoria.

A partir das falas dos estudantes percebe-se que durante as visitas nos serviços e as discussões com os profissionais, os estudantes puderam compreender, de forma mais concreta, como funciona o trabalho em Redes e como os profissionais desenvolvem esse processo nos níveis de atenção que compõem o SUS.

Nessa direção, faz-se necessário mencionar que, além de oportunizar aos estudantes compreender de forma mais significativa as ideias e experiências oportunizadas mediante as vivências nos espaços de ensino e de serviço no âmbito do SUS, também reforçam que a transformação das práticas assistenciais requer o aprimoramento dos processos de ensino, visando à melhoria da qualidade dos serviços.

\section{CONSIDERAÇÕES FINAIS}

O programa VER-SUS pode ser considerado uma valiosa ferramenta para que os acadêmicos possam conhecer e reconhecer as RAS. As atividades desenvolvidas qualificam, 


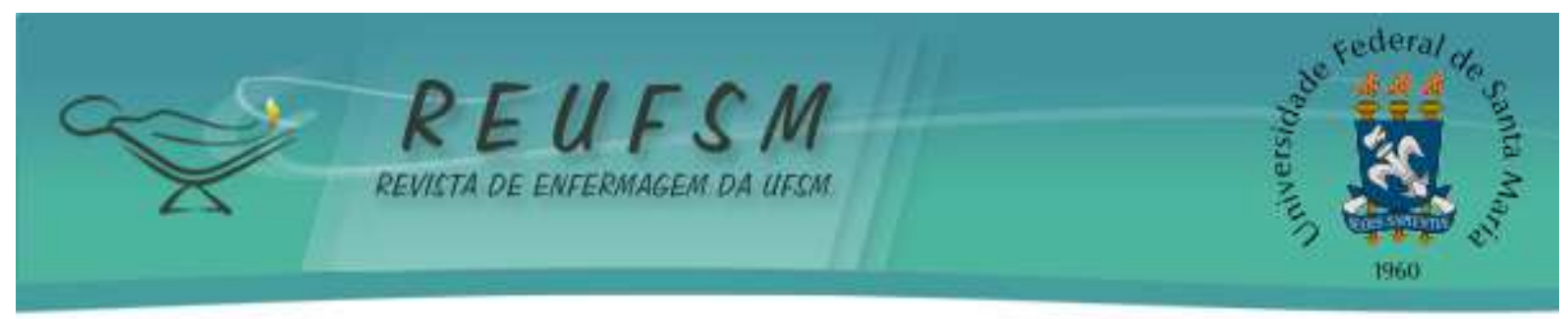

consideravelmente, a formação dos futuros profissionais da saúde. Contudo, é preciso lembrar que apenas parte dos estudantes acessa o Programa, portanto, sugere-se a ampliação do mesmo e, também, que o tema seja dialogado em outros espaços de formação.

A pesquisa indicia incipiência quanto às discussões sobre as RAS na formação em Enfermagem. Portanto, é eminente a necessidade de reavaliação por parte do corpo docente das IES, dos conteúdos ministrados em sala de aula, no sentido de instigar abordagens sobre a temática com maior problematização e frequência.

Por fim, retomam-se os persistentes desafios na efetivação das práticas dialógicas em espaços diversificados, no âmbito da formação, destacando-se contribuições significativas à reorientação do ensino e também da práxis, como por exemplo, a adesão de estudantes ao VER-SUS.

Como limitação do estudo se reconhece a impossibilidade de generalização dos resultados, tendo em vista que é uma pesquisa com metodologia qualitativa, assim, os resultados encontrados estão relacionados à trajetória, experiência e significações dos sujeitos investigados. Ainda, julga-se importante a realização de pesquisas que explorem as fragilidades e potencialidades desse e de outros Programas que visam à reorientação da formação em saúde.

\section{REFERÊNCIAS}

1. Brasil. Presidência da República. Decreto $n^{\circ} 7.508$, de junho de 2011. Regulamenta a Lei $\mathrm{n}^{\circ}$ 8.080, de 19 de setembro de 1990, para dispor sobre a organização do Sistema único de Saúde - SUS, o planejamento da saúde, a assistência à saúde e a articulação interfederativa [Internet]. 2011 [acesso em 2016 dez 10]. Disponível em: http://www.planalto.gov.br/ccivil_03/_ato2011-2014/2011/decreto/D7508.htm.

2. Mendes EV. Comentários sobre as Redes de Atenção à Saúde no SUS. Divulg Saúde Debate [Internet]. 2014 [acesso em 2016 dez 10];52:38-50. Disponível em: http://cebes.org.br/site/wp-content/uploads/2014/12/Divulgacao-52.pdf.

3. Mendes EV. As redes de atenção à saúde. Ciênc Saúde Colet [Internet]. 2010 [acesso em 2016 dez 10];15(5):2297-305. Disponível em: http://www.scielo.br/pdf/csc/v15n5/v15n5a05.pdf.

4. Silva SF. Organização de redes regionalizadas e integradas de atenção à saúde: desafios do Sistema Único de Saúde (Brasil). Ciênc Saúde Coletiva [Internet]. 2011 [acesso em 2016 dez 10];16(6):2753-62. Disponível em: http://www.scielo.br/pdf/csc/v16n6/14.pdf.

5. Lopes RE, Silva AC, Nóbrega-Therrien SM. Formação reflexiva no ensino da enfermagem: discussão à luz de Schön. Cad Pesqui [Internet]. 2015 [acesso em 2016 dez 10];22(1):47-58. Disponível em: http://dx.doi.org/10.18764/2178-2229.v22.n1.p.47-58.

6. Vasconcelos CMCB, Backes VMS, Gue JM. Avaliação no ensino de graduação em enfermagem na America Latina: uma revisão integrativa. Enferm Glob [Internet]. 2011 


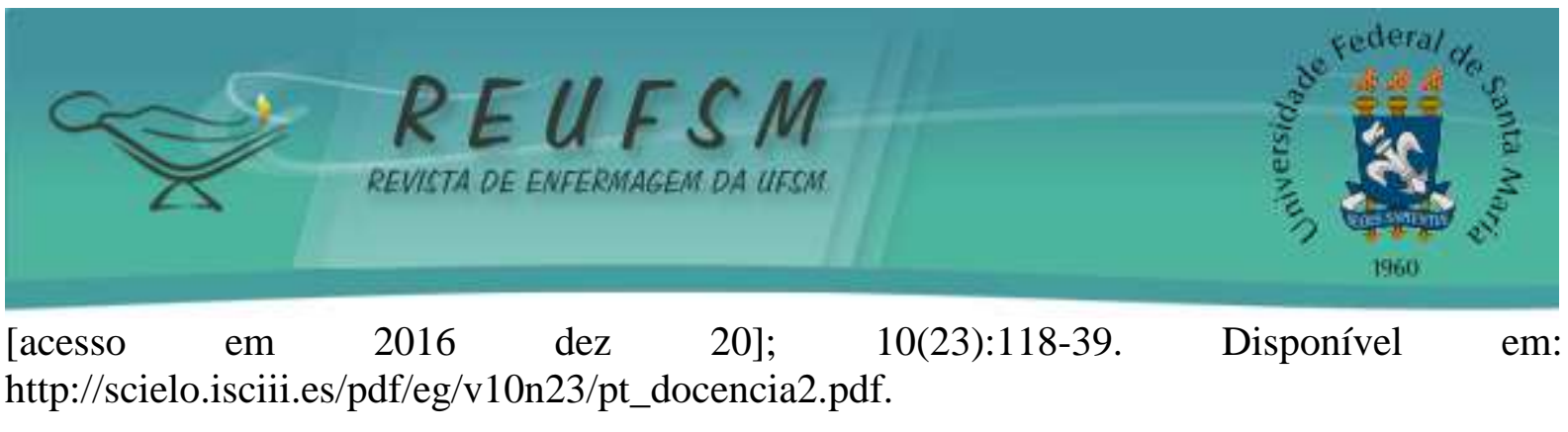

7. Oliveira MCM, Lima TL, Baluta VH. A formação do profissional enfermeiro, no contexto das reformas de ensino, no Brasil. Rev Grifos [Internet]. 2014 [acesso em 2016 dez 20];23(36/37):161-86.

Disponível

em:

http://bell.unochapeco.edu.br/revistas/index.php/grifos/article/view/2784/1766.

8. Conselho Nacional de Educação. Câmara de Educação Superior. Resolução CNE/CES no 03, de 07 de novembro de 2001. Diretrizes Curriculares Nacionais do curso de graduação em enfermagem. Diário Oficial da União, Brasília; 2001 nov 09. Seção 1, p. 37.

9. Fernandes JD, Florencio RMS, Silva RMO, Silva LS, Teixeira GA, Rebouças LCC. Aderência de cursos de graduação em enfermagem às diretrizes curriculares nacionais na perspectiva do Sistema Único de Saúde. Esc Anna Nery Rev Enferm [Internet]. 2013 [acesso em jul 13];17(1):829. Disponível em: http://www.scielo.br/scielo.php?script=sci_arttext\&pid=S141481452013000100012 .

10. Brasil. Ministério da Saúde. Secretaria de Gestão do Trabalho e da Educação na Saúde. Departamento de Gestão da Educação na Saúde. VER-SUS Brasil: caderno de textos. Brasília (DF): Ministério da Saúde; 2004. (Série B. Textos Básicos de Saúde).

11. Weber A, Tombini LHT, Colliselli L, Albrecht CC, Macari L, Favero FM. Vivências e estágios na realidade do SUS (VER-SUS) e a formação profissional em saúde: relato de experiência. Rev Eletrônica Extensão [Internet]. 2016 [acesso em 2017 jul 13];13(23):112-22. Disponível em: https://periodicos.ufsc.br/index.php/extensio/article/view/18070221.2016v13n23p112.

12. Maffissoni AL, Vicari G, Menegatti MS, Dervanoski C, Silva Filho CC. VER-SUS Oeste Catarinense: vislumbrando um itinerário formativo em enfermagem direcionado ao Sistema Único de Saúde. Rev Enferm UFPE [Internet]. 2017 [acesso em 2017 jan 14];11(2):758-64. Disponível em: http://www.periodicos.ufpe.br/revistas/revistaenfermagem/article/view/11997/14568.

13. Cassiani SHB, Bassalobre-Garcia A, Reveiz L. Acesso universal à saúde e cobertura universal de saúde: identificação de prioridades de pesquisa em enfermagem na América Latina. Rev Latinoam Enferm [Internet]. 2015 [acesso em 2017 mar 16];23(6):1195-208. Disponível em: http://www.scielo.br/scielo.php?pid=S0104-11692015000601195\&script=sci_arttext\&tlng=pt.

14. Bardin, L. Análise de conteúdo. São Paulo: Edições 70; 2011.

15. Vendruscolo C, Prado ML, Kleba ME. Formação de recursos humanos em saúde no Brasil: uma revisão integrativa. Educ Rev [Internet]. 2014 [acesso em 2016 dez 20];30(1):215-44. Disponível em: http://www.scielo.br/scielo.php?pid=S0102$46982014000100009 \&$ script=sci_abstract\&tlng=pt.

16. Barlem JG, Lunardi VL, Barlem ELD, Bordignon SS, Zacarias CC, Lunardi Filho WD. Fragilidades, fortalezas e desafios na formação do enfermeiro. Esc Anna Nery Rev Enferm [Internet]. 2012 [acesso em 2016 dez 20];16(2):347-53. Disponível em: http://www.scielo.br/scielo.php?script=sci_arttext\&pid=S1414-81452012000200020.

17. Medeiros VC, Peres AM. Atividades de formação do enfermeiro no âmbito da atenção básica à saúde. Texto \& Contexto Enferm [Internet]. 2011 [acesso em $2016 \mathrm{dez}$ 20];20(N 


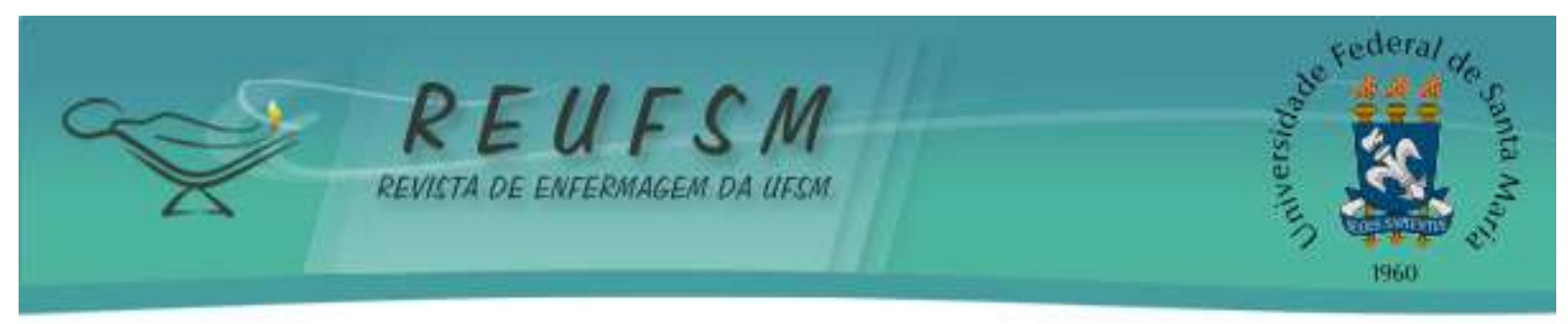

Esp):27-35. Disponível em: http://www.scielo.br/scielo.php?script=sci_arttext\&pid=S010407072011000500003.

18. Abrahão AL, Merhy EE. Formação em saúde e micropolítica: sobre conceitos-ferramentas na prática de ensinar. Interface Comum Saúde Educ [Internet]. 2014 [acesso em 2016 dez 20];18(49):313-24. Disponível em: http://www.scielo.br/scielo.php?script=sci_arttext\&pid=S141432832014000200313.

19. Ceccim RB, Feuerwerker LC. O quadrilátero da formação para a área da saúde: ensino, gestão, atenção e controle social. Physis [Internet]. 2004 [acesso em 2016 dez 20];14(1):41-65.

Disponível em:

http://ltcead.nutes.ufrj.br/constructore/objetos/O\%20Quadril\%e1tero\%20da\%20Forma\%e7\%e3o\% 20para\%20a\%20\%c1rea\%20da.pdf.

20. Vendruscolo C, Trindade LL, Krauzer IM, Prado ML. A inserção da universidade no quadrilátero da educação permanente em saúde: relato de experiência. Texto \& Contexto Enferm [Internet]. 2016 [acesso em 2016 dez 20];25(1):1-7. Disponível em: http://www.scielo.br/pdf/tce/v25n1/0104-0707-tce-25-01-2530013.pdf.

21. Merhy, EL. Saúde: a cartografia do trabalho vivo em ato. São Paulo: Hucitec; 2007.

Data de submissão: 12/02/2017

Data de aceite: 17/08/2017

Contato do autor principal: André Lucas Maffissoni

Endereço postal: Rua Sete de Setembro, 68E, Centro. CEP: 89815-630. Chapecó, SC. Brasil. E-mail: andremaffissoni@ hotmail.com 